\title{
A tribute to Thomas Roosevelt Punnett, Jr. (1926-2008)
}

\author{
William Hagar · Hope Punnett · Laura Punnett - Govindjee
}

Received: 4 July 2011/ Accepted: 24 September 2011/Published online: 11 October 2011

(C) Springer Science+Business Media B.V. 2011

\begin{abstract}
We honor here Thomas (Tom) Roosevelt Punnett, Jr. (May 25, 1926-July 4, 2008), who was a pioneer of Biology, particularly of biochemistry of plants and algae, having specialized in photosynthesis under Robert Emerson of the University of Illinois at UrbanaChampaign. He did exciting work on regulation and control of various metabolic reactions. He was an innovator and raconteur par excellence, and he prized critical thinking. His enthusiasm for basic science questions was matched by his grasp of their "real-world" implications. His last project was a patent for anaerobic sewage treatment that he hoped would lead to solution of waste disposal and energy
\end{abstract}

Editorial Note This tribute to Thomas Roosevelt Punnett, an alumnus of the distinguished Photosynthesis Project of the Robert EmersonEugene Rabinowitch research group at the University of Illinois at Urbana-Champaign (UIUC), is a part of the history of photosynthesis research (See Rabinowitch (1961) on Emerson; Bannister (1972) on Rabinowitch; Brody (1992) on Rabinowitch; Ghosh (2004) on his time in the Lab; and Govindjee (2004) on both Emerson and Rabinowitch.) - This article was edited, and accepted for publication by George C. Papageorgiou, a former member of the photosynthesis research group at the UIUC.-Govindjee, Founding Historical Corner Editor.

W. Hagar $(\bowtie)$

Department of Biology, College of Science and Mathematics, University of Massachusetts Boston, 100 Morressey Boulevard, Boston, MA 02125, USA

e-mail: william.hagar@umb.edu

\section{H. Punnett}

Department of Pediatrics, Temple University Medical School, Philadelphia, PA 19140, USA

e-mail: hpunnett@verizon.net

L. Punnett

Department of Work Environment, University of Massachusetts Lowell, Lowell, MA 01854, USA

e-mail: Laura_Punnett@uml.edu creation world wide, including the clean-up of Lake Erie, where he had sailed as a boy. On the personal side, he had a strong sense of morality and a great wit and humor.

Keywords Chlorella pyrenoidosa $\cdot$ Elodea $\cdot$ Robert Emerson · Robin Hill · Leukocyte · Methane production from organic material - Eugene Rabinowitch - Temple University · University of Illinois at Urbana-Champaign . University of Rochester · Yale University

\section{Early life and education}

Thomas Roosevelt Punnett, Jr., biochemist and Professor Emeritus at Temple University, was born in Buffalo, New York, on May 25, 1926. There, he attended Nichols School, a small preparatory educational establishment (for boys at that time), to which he maintained great loyalty all his life. Upon graduation (Fig. 1), in 1944, he volunteered for immediate induction in the US Army, serving in Japan, Korea, and the Phillipines.

Govindjee

Department of Plant Biology, University of Illinois

at Urbana-Champaign, Urbana, IL 61801, USA

e-mail: gov@illinois.edu

Govindjee

Department of Biochemistry and Center of Biophysics \& Computational Biology, University of Illinois at Urbana-Champaign, Urbana, IL 61801, USA 


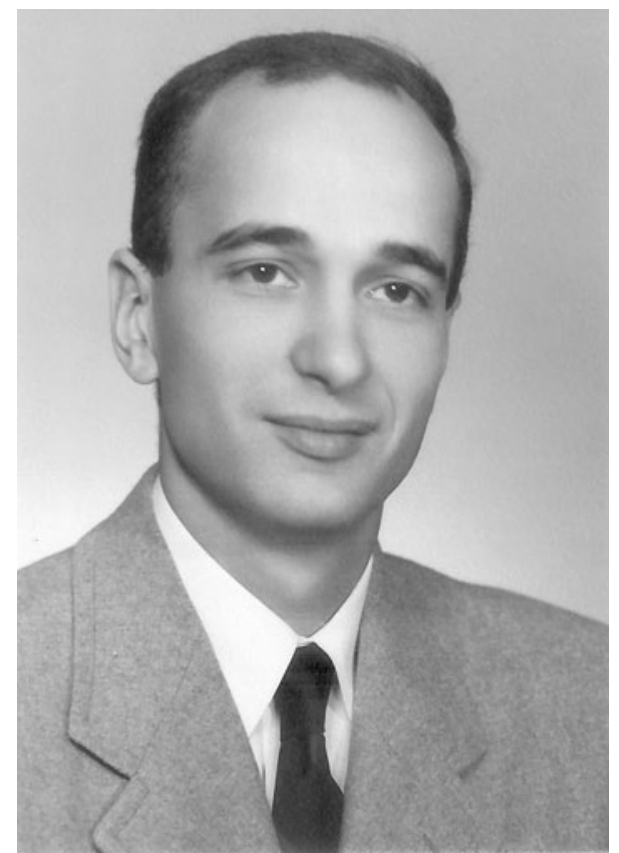

Fig. 1 Thomas (Tom) Punnett's graduation portrait, Nichols School, Buffalo NY, 1944

Tom entered Yale University after his discharge from the army in 1946, receiving his B.S. in Chemistry in 1950. That same year he married Hope Handler, whom he had met at Yale where she was a graduate student in Genetics.

Tom enrolled in the Graduate College of the University of Illinois at Urbana-Champaign in September of 1950, and worked in the laboratory of Robert (Bob) Emerson. Besides Emerson, his doctoral committee included Eugene Rabinowitch (physical chemist), Sol Spiegelman (microbiologist), R.D. Rawcliffe (physicist), Carl S. Vestling (biochemist), and I.C. (Gunny) Gunsalus (biochemist). This was an outstanding group of scholars for a young research plant biologist to train with. Even before his doctoral thesis, Tom published a paper in Nature on oxygen evolution in algal chloroplast (Punnett and Fabiye 1953). This provided the first direct method for comparing the activities in vitro and in vivo of the photochemical systems in Chlorella, an organism widely used in the study of in vivo photosynthetic reactions.

During his time in Emerson's laboratory, Tom attended the first Gatlinburg Conference in 1952, one of the earliest photosynthesis conferences in USA with an international participation. (See Tom with Emerson in Fig. 2 [top and bottom], and with Rabinowitch in Fig. 3.)

Marcia Brody, who had later joined Emerson's lab, recently told one of us (Govindjee): "When I came to Emerson's lab, Tom was there. He was extremely kind, and could not have been kinder; he was very helpful to me; he
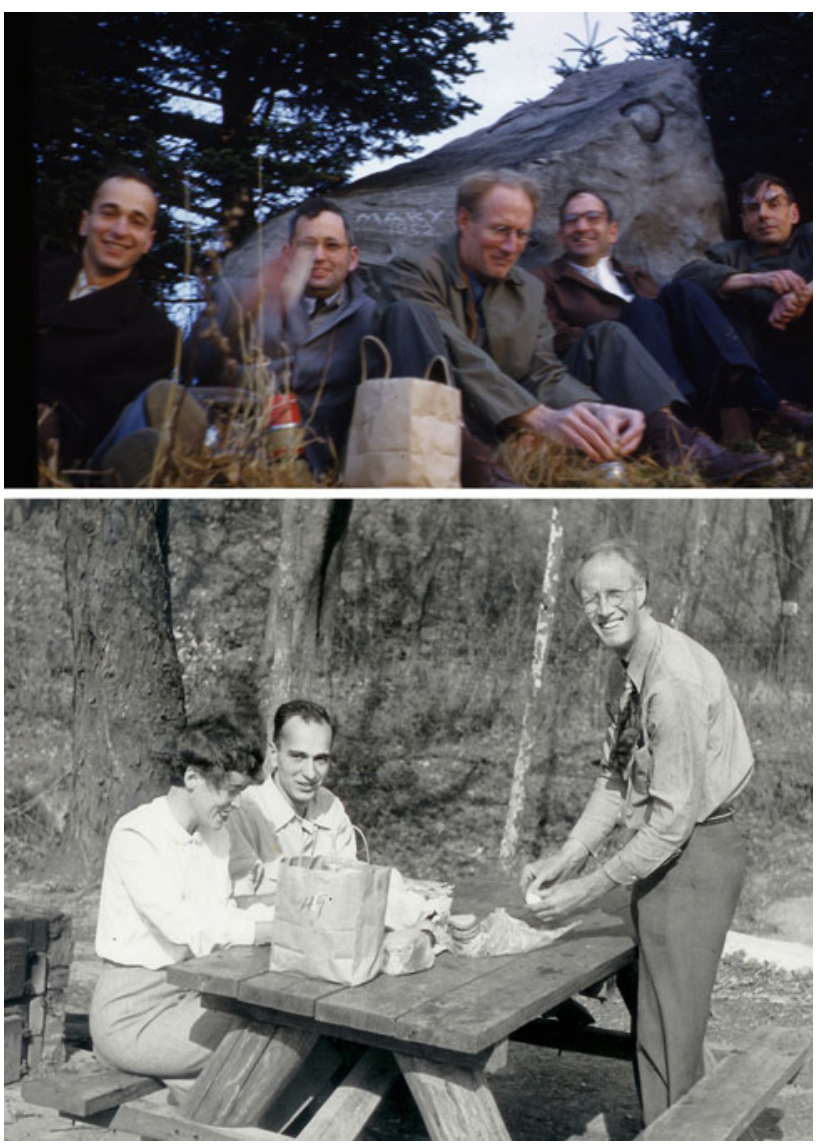

Fig. 2 Top (Left to right) Tom Punnett, Albert Frankel, Robert Emerson, David Goddard, and Robin Hill at a sunrise hike in the Smoky Mountains, outside Gatlinburg, 1952. Bottom At a picnic in Illinois: Robert Emerson is standing, wearing a tie, and peeling an egg; Hope and Tom Punnett are sitting. Photo taken by Robin Hill on the way to Gatlinburg, 1952

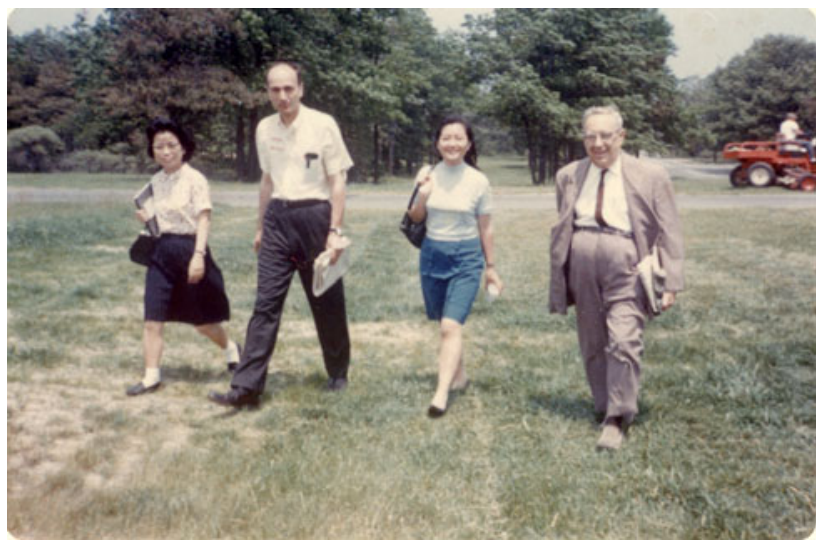

Fig. 3 Tom Punnett (second from left) and Eugene Rabinowitch (fourth from left) walking with two international scientists, Urbana IL, circa 1952-1953

was a thoughtful and a generous person, and had a good sense of humor. He was a very dedicated scientist."

Steve Brody, then a student of Rabinowitch, wrote, before he died: 
I remember [Tom and Hope Punnett] from my days at the University of Illinois in the 1950s rather well. We all used to play bridge in their house, on hot summer days in Urbana. Tom was a most friendly, helpful coworker in Emerson's lab. Emerson thought very highly of him. Emerson had recommended that Tom do a post-doc in England with Robin Hill, and he did go to Cambridge for that.

(See a Tribute to Steve Brody by Hirsch et al. 2010.)

\section{Academic and research life}

After receiving his Ph.D. (Punnett 1954), Tom began a postdoctoral fellowship in biochemistry at Cambridge University, England, where he worked with Robert (Robin) Hill on the influence of environmental conditions on photosynthesis. At this time no one knew about the two photosystems in plants (for Timeline of discoveries in photosynthesis, see Govindjee and Krogmann 2004). Hill (1937, 1939) had found that the oxygen evolving part of photosynthesis could be separated from the carbon dioxide fixation part by using an electron acceptor such as ferricyanide. Tom combined this "Hill" reaction and his own experience with the single cell alga, Chlorella pyrenoidosa. Chlorella was the organism of choice as it was easy to grow and could be used directly in gas exchange measurements using Warburg manometers or oxygen electrodes.

Derek Bendall, of the UK, wrote:

Tom and Hope were very kind to us when we were on sabbatical in Philadelphia 1968-1969 with a young family. He always seemed to be brimming over with a youthful enthusiasm for science and for his experiments, despite suffering at least his fair share of difficulties and setbacks.. What Tom had been doing for his Ph.D. with Emerson fitted very well with one of Robin Hill's main research interests at the timenatural electron acceptors...., except that Tom had been working mainly with Chlorella.... Robin got him to spend much of his time with plant material....

Returning to the United States in 1956, Tom joined the faculty of the University of Rochester where he stayed for 7 years. His research efforts were focused primarily in photosynthesis, but he also published a paper with his wife, Hope (one of the authors of this Tribute), in Nature, on a leukocyte growth factor isolated from red beans (Punnett and Punnett 1963; Punnett et al. 1962). Later, Punnett et al. (1980) did an analysis of hydrozoan sperm attractant. His understanding of biochemical techniques including processes for the purification of proteins was exceptional.

The primary focus of Tom's research life remained an unquenchable interest in photosynthesis, stemming from the early experiments of Robert Emerson on photosynthetic processes in plants. Emerson and Lewis (1943) had found that the quantum yield of photosynthesis dropped precipitously when algae were illuminated beyond $685 \mathrm{~nm}$ (the so-called Red Drop). A major breakthrough came when Emerson et al. (1957) discovered a synergistic effect by illuminating algae with two beams together, one in the red drop region and another on the short-wave side of the spectrum. This phenomenon, now known as the Emerson Enhancement Effect, implied that there were two photosystems involved in the photosynthetic process. Emerson's enhancement experiment was the seminal experiment for establishing the two light system hypothesis in plant photosynthesis (also see Govindjee and Rabinowitch 1960; Myers and French 1960). During this period, Punnett (1959) continued his experiments with broken chloroplasts along with their uncertainties, and this moved him toward techniques for proper isolation of chloroplasts.

Tom moved to the Biology Department at Temple in 1963 (Fig. 4), serving twice as Acting Chair in his long tenure there. In the early 1960s, the department was becoming more engaged in research and the young, active plant physiologist was just the addition the department needed. During this period, Tom published the work he had done earlier on improved methods for studying the Hill

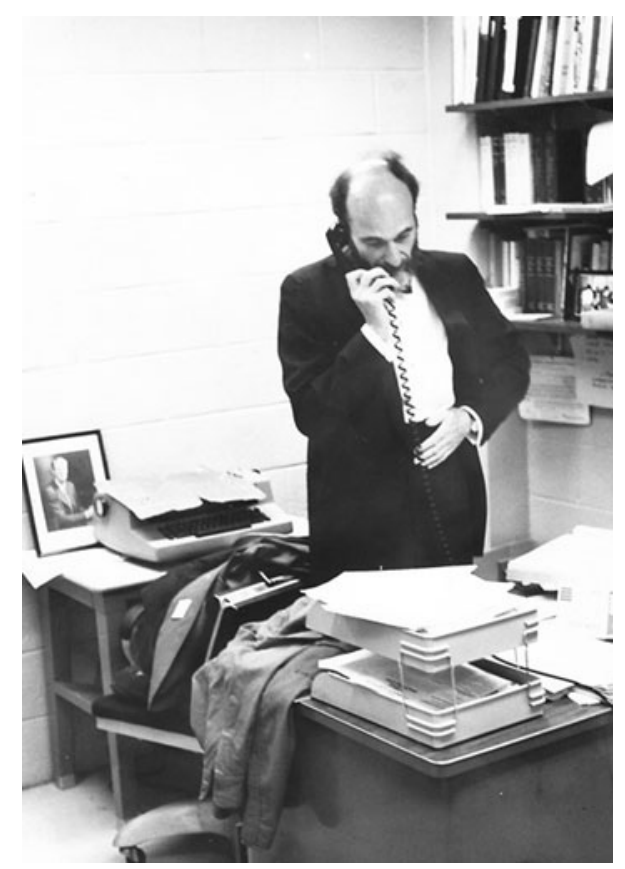

Fig. 4 Tom Punnett in his office, with a photograph of Bob Emerson; on the book shelf are Volume 1, Volume 2 (Part 1) and Volume 2 (Part 2) of Rabinowitch's classic monograph (1945-1956) on "Photosynthesis"; in the Preface of Volume 2 (Part 1, 1951), Rabinowitch thanked Tom Punnett for his "valuable aid in the reading of the proofs and the checking of the bibliography". Photo taken at Temple University, Philadelphia PA 
reaction (Punnett 1957; Punnett et al. 1964) and on an enhancement of the Hill reaction and photophosphorylation by $\mathrm{CO}_{2}$ (Punnett and Iyer 1964; cf. Govindjee et al. 1964 for Emerson Enhancement in NADP Hill reaction by different wavelengths of light). The new effect of $\mathrm{CO}_{2}$ on photophosphorylation was called "Punnett Effect" by Govindjee and van Rensen (1978).

Tom was very much interested in the environmental factors that might influence in vivo and subsequent in vitro results with the isolation of chloroplasts. He became interested in plant growth conditions prior to photosynthesis measurements with either intact plants or isolated chloroplasts. One of his research papers from the Temple University showed that growth conditions of the plant resulted in differences in enhancement of photophosphorylation by $\mathrm{CO}_{2}$ (Punnett 1965). This experiment set his research direction for the next few years. He soon presented his paper on isolation of non-granular chloroplasts from higher plants (Punnett 1966).

Tom started to work again with $C$. pyrenoidosa to study the changes in development and photosynthesis that occur during the life cycle of this alga. Punnett and Derrenbacker (1966) described the aminoacid composition of algal cell walls. He and one of us (Hagar) developed synchronization techniques to have most of the cultured cells complete their life cycle in $24 \mathrm{~h}$; thus, they were able to look at developmental stages a few hours apart and to monitor the in vivo changes in pigment protein compositions while they measured photosynthetic rates of the cell culture. They also described the synchronization process and the unique use of Probit Analysis to better follow and characterize cell synchrony (Hagar and Punnett 1973).

During this time, Tom also focused on the aquarium plant, Elodea, to investigate the relationship between in vivo and in vitro measurements. He was especially intrigued with literature reports of granular or homogenous chloroplasts and the isolation of such "intact" chloroplasts (Sager and Palade 1956). He found that pretreatment of Elodea with red or blue light would cause a change in the observable chloroplast structure. With red light, he could push the plant into a more homogeneous state where granular stacks could not be observed. He developed the methodology to isolate chloroplasts with visible grana stacks. Punnett et al. (1981) reported that chloroplasts undergo rapid rearrangements in vivo. By this time it was known that there were two photosystems connected by an electron transport chain. Tom found that the Emerson Enhancement effect was not observed under conditions when the two photosystems are well balanced; the effect is seen only when there is an unbalanced excitation of the systems (Punnett 1970). This is a very important observation because lack of Emerson Enhancement must never be taken as evidence of the absence of two light reactions and two photosystems.
Tom extended the work on Elodea to demonstrate that the sensitivity of chloroplast structure to environmental conditions, as observed by both light and electron microscopy, was also present in terrestrial plants (Punnett and Kelly 1975, 1976). This transformation was achieved with plants from nine different genera, including both monocotyledonous and dicotyledonous plants with either Kranz or conventional leaf anatomy.

Tom's homogeneous chloroplast did not show the Emerson enhancement effect, but his grana stack chloroplasts did show it for the first series of measurements. Thus, Tom was able to prepare intact plants that would exhibit differences in enhancement due to different states of plant tissue. This may be related to the so-called State changes studied by Bonaventura and Myers (1969) and Murata (1969), among others (see a historical review on state changes by Papageorgiou and Govindjee 2011).

The other control mechanism that Tom worked on was the problem of metabolites that could not be accounted for by either the Calvin-Benson cycle or ß-carboxylation. Thus, his two major research directions, both involving work on control mechanisms, led Tom to find himself in a position of confronting scientific orthodoxy, which he had not set out to do.

Tom postulated that the unexplained metabolites indicated the existence of two or more $\mathrm{CO}_{2}$ fixation pathways, whose relative rates are controlled by environmental conditions. Again, wavelength and intensity of light and humidity were shown to modify these pathways. His work involved the search for the quantifiable and reproducible conditions under which these proposed pathways could occur. This led him to an interest in learning the technique of photoacoustic spectroscopy, as developed by Shmuel Malkin (Weizmann Institute). Tom worked as a Meyerhof Fellow, in Malkin's laboratory, where he was able to investigate his hypothesis concerning the reverse Krebs cycle. However, he was frustrated by his inability to identify all of the necessary environmental conditions and to reproduce the same result after he returned to Temple University, where he had less than ideal conditions for growing plants.

Shmuel Malkin wrote,

... [Tom] came to me to learn all about the photoacoustic method and its use in photosynthesis. He was a very social and enthusiastic person. He was very happy about the method and the information that it gave him about the photosynthesis of palisade mesophyll vs. spongy mesophyll cells. He used to walk in the lab and talk about it very loudly and proudly. I remember him showing me how he grows plants, the special soil that he had designed for the plants and how the growth conditions affected photosynthesis (from the photoacoustic results)... 
(See Punnett (1987) that describes his work with photoacoustic spectroscopy in understanding environmental control of photosynthetic enhancement.)

\section{Teaching, his collaborative spirit, and who he really was}

At Temple, many students relied on the affable and talented professor not only in his own laboratory but also in other laboratories, when faculty members left for one reason or another. A former student, Howard Nields, put it, “..we were orphans of the storm, and Tom Punnett graciously became our foster father, so to speak." Tom took on this advising with compassion, critical scientific input, and unbridled energy. He redirected some graduate students toward more promising research endeavors, and he guided others to successful careers in academic settings. His record during this cohort cycle was six doctoral theses.

Tom collaborated with colleagues in Chemistry to develop an inter-departmental Biochemistry program, which he directed for a number of years. He worked with fellow faculty members and students to solve a wide range of problems from purifying sperm attractants from starfish (Punnett et al. 1992) to comparing chlorophyll protein complexes of plants and photosynthetic bacteria for environmental control of photosynthesis (Webb and Punnett 1989). He was a visiting professor at University College, London, U.K. (1968-1969), spent one sabbatical at the Research Institute for Advanced Studies (RIAS) in Baltimore with Bessel Kok (1961), another leave at the Weizmann Institute in Rehovot, Israel (1986), as mentioned above, and his last at the US Department of Agriculture (USDA) in Beltsville, MD (1991).

Tom enjoyed his students and he loved teaching, which was not a rote activity; he never gave the same lecture twice. He communicated the scientific process as a series of trials and errors undertaken by fallible human beings. Biographical information about the researchers whose work he discussed enlivened his lectures. He prized critical thinking and was careful to make sure his students solved their own scientific problems. He instilled the ability to see multiple viewpoints and ask the pertinent questions.

To his students, Tom Punnett was an innovator and a captivating lecturer. His wicked wit was as evident as his strong sense of morality. He was a caring mentor, helping his students with everything from language skills to job and graduate school applications. Those completing their doctorates with him went on to successful scientific careers, often using his teaching techniques to stimulate students of their own. He encouraged undergraduate students to join his research group. He took them to scientific meetings, along with graduate students, where they had the opportunity to hear results challenged and theories debated. $\mathrm{He}$ knew his students' families and he enjoyed entertaining them at home.

Tom's enthusiasm for basic science questions was matched by his grasp of their "real-world" implications. Only a year before he died, he had applied for a patent (International Publication Number WO 2008/002448 A2: A method of maximizing methane production from organic material) to optimize anaerobic metabolism of municipal wastes. The process has the potential to greatly diminish solid waste while leading to high production of economically valuable methane. Additional benefits would be an increase in the purity of sewage plant output discharged into receiving waters, reduction of $\mathrm{CO}_{2}$ released to the atmosphere when biologically generated methane is used as fuel and production of a final sludge that, when pasteurized, could be used as a nutritious soil additive. Unfortunately, he did not live to complete the experimental validation procedures.

Although he retired from teaching when health problems made it necessary, he continued his research until his death. His never failing force of will and sense of humor enabled him to keep going. He stayed abreast of developments in the field, attending Gordon Conferences and international meetings. In 2005, his scientific colleagues recognized him when they asked him to chair the Eastern Regional Photosynthesis Conference. His choice of invited speakers gave evidence of how closely he followed seminal research efforts in the area. He attended all but one of the Eastern Regional Photosynthesis Conferences during the past 25 years including the meeting in 2008 , just a few weeks before his final illness.

Tom Punnett was a history and archeology buff, an avid connoisseur of classical music, and an enthusiastic gardener. He grew up sailing on Lake Erie, which inspired a life-time passion both for sailing and for the natural

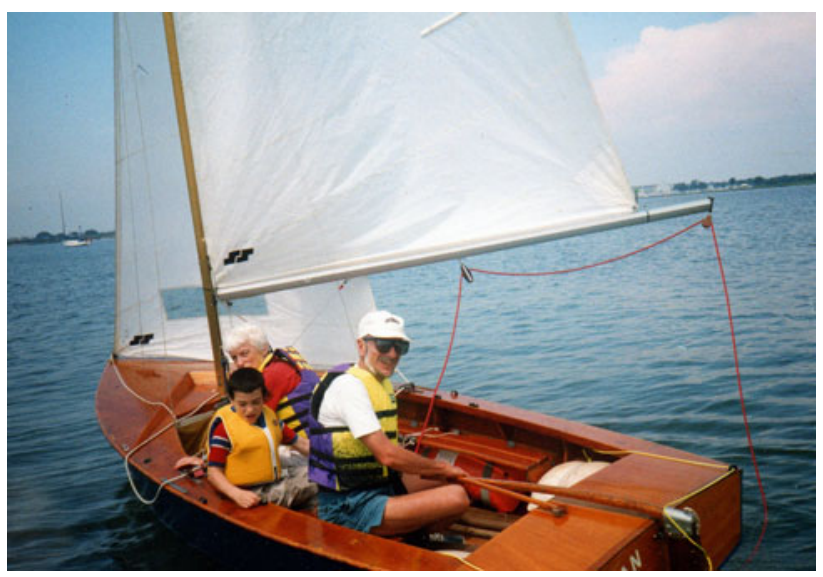

Fig. 5 Tom and Hope Punnett in their sail boat in 1996; the child is Yitzhak Goldberg, their oldest grandson 


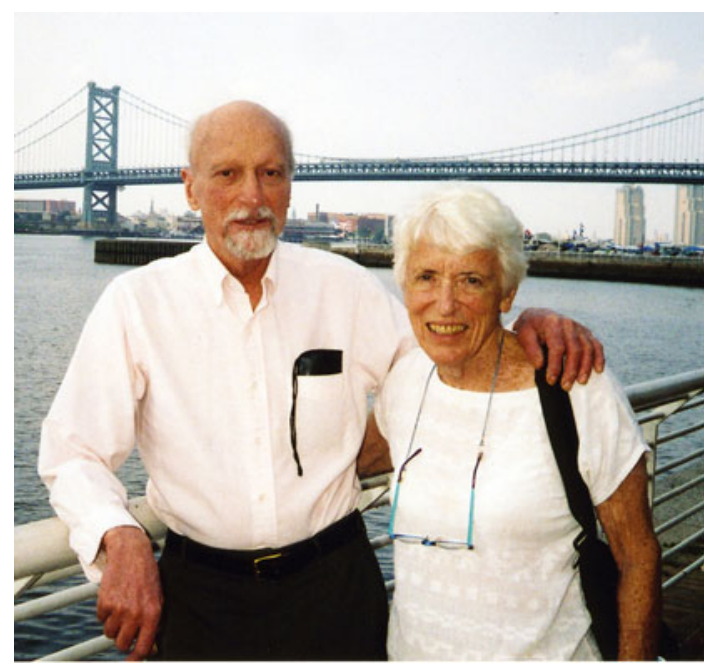

Fig. 6 Tom and Hope Punnett, Philadelphia PA, 2007

environment. Combined with his scientific interests, these led him to an early appreciation of ecology and the need for environmental protection. In the days of the Cold War and nuclear threat, he helped to found the Rochester Committee for Scientific Information, an early environmental action and study group. In Philadelphia he was active in the Sierra Club, providing technical information on issues such as water quality.

His zest for life was evident in everything he did, from playing with his grandchildren to playing the stock market. He was a competitive sailor, racing his 14-foot dinghy with any available family member as crew (Fig. 5). He built and raced a wooden Sunfish, "frostbiting" in the now defunct Schuylkill Sailing Association mid-winter regattas and serving as Commodore of the same for several years. Already into his retirement, he discovered a weekly pickup soccer game on Temple's athletic fields and quickly became a regular. He scored the first three goals of his life on his 78th birthday. The signed soccer ball still sits above the desk in his study.

In conclusion, all of us have been most impressed by Tom's resiliency: His unbridled enthusiasm for research and teaching provided a wonderful academic foundation for all of his students, colleagues and all those who came in contact with him at scientific meetings. Nothing dampened his spirit. He is survived by his wife of 58 years, Hope Handler Punnett (Fig. 6), Emeritus Professor of Pediatrics, Temple University School of Medicine; 3 daughters, Laura Punnett (one of the authors of this Tribute), Professor of Work Environment, University of Massachusetts Lowell; Susan Punnett, Director, Family and Youth Initiative; Jill Goldberg, flautist, engineer and technical writer; and his seven grandchildren, Lynn, Hanni, Yitzhak, Sam, Efraim, Rafael, and Ruhama. Tom Punnett had a worldwide extended family, including exchange "daughters," medical students, and social workers who enjoyed his hospitality and appreciated his strong sense of justice and his commitment to making the world a better place to live.

Acknowledgment We thank George C. Papageorgiou, who knew several members of the Emerson-Rabinowitch Photosynthesis Project, for his valuable suggestions, and for editing the final copy of this manuscript. George was our guest editor, who enthusiastically recommended acceptance of this Tribute for publication in Photosynthesis Research.

\section{References}

Bannister TT (1972) The careers and contributions of Eugene Rabinowitch. Biophy J 12:707-718

Bonaventura C, Myers J (1969) Fluorescence and oxygen evolution from Chlorella pyrenoidosa. Biochim Biophys Acta 89:366383

Brody SS (1992) We remember Eugene [Rabinowitch] and his lab during the fifties. Photosynth Res 43:67-74

Emerson R, Lewis CM (1943) The dependence of the quantum yield of Chlorella photosynthesis on wavelength of light. Am J Bot 30:165-178

Emerson R, Chalmers RV, Cederstrand CN (1957) Some factors influencing the long wave limit of photosynthesis. Proc Natl Acad Sci USA 43:133-143

Ghosh AK (2004) Passage of a young Indian physical chemist through the world of photosynthesis research at Urbana, Illinois in the 1960s: a personal essay. Photosynth Res 80:427-437

Govindjee, Krogmann D (2004) Discoveries in oxygenic photosynthesis (1727-2003): a perspective: dedicated to the memories of Martin Kamen (1920-2002), William A. Arnold 1904-2001). Photosynth Res 80:15-57

Govindjee, Rabinowitch E (1960) Two forms of chlorophyll $a$ in vivo with distinct photochemical functions. Science 132:159-160

Govindjee, van Rensen JJS (1978) Bicarbonate effects on the electron flow in isolated broken chloroplasts. Biochim Biophys Acta 505:183-213

Govindjee R, Govindjee, Hoch G (1964) Emerson enhancement effect in chloroplast reactions. Plant Physiol 39:10-14

Hagar W, Punnett T (1973) Probit transformation: improved method for defining synchrony of cell cultures. Science 182:1028-1030

Hill R (1937) Oxygen evolution by isolated chloroplasts. Nature 139:881-882

Hill R (1939) Oxygen produced by isolated chloroplasts. Proc R Soc Lond Ser B 127:192-210

Hirsch RE, Rich M, Govindjee (2010) A tribute to Seymour Steven Brody: in memoriam (November 29, 1927 to May 25, 2010). Photosynth Res 106:191-199

Murata N (1969) Control of excitation transfer in photosynthesis. I. Light-induced changes of chlorophyll a fluorescence in Porphyridium cruentum. Biochim Biophys Acta 172:242-251

Myers J, French CS (1960) Evidences from action spectra for a specific participation of chlorophyll $b$ in photosynthesis. J Gen Physiol 43:723-736

Papageorgiou GC, Govindjee (2011) Photosystem II fluorescence: slow changes-scaling from the past. J Photochem Photobiol B 104:258-270

Punnett T (1957) The pH optimum of the Hill reaction. J Am Chem Soc 79:4816-4817

Punnett T (1959) Stability of isolated chloroplast and its effect on Hill reaction measurements. Plant Physiol 34:283-289 
Punnett T (1965) Influence of growth conditions on the enhancement of photophosphorylation by carbon dioxide. Plant Physiol 40:1283-1284

Punnett T (1966) The isolation of nongranular chloroplasts from higher plants. Brookhaven Symp Biol 19:375-379

Punnett T (1970) Environmental control of photosynthetic enhancement. Science 171:284-286

Punnett T (1987) Environmental control of photosynthetic enhancement in palisade mesophyll chloroplasts measured by photoacoustic spectroscopy. In: Biggins J (ed) Progress in photosynthesis research, vol 2. Nijhoff, Dordrecht, pp 753-756

Punnett T, Derrenbacker EC (1966) The amino acid composition of algal cell walls. J Gen Microbiol 44:105-114

Punnett T, Fabiye A (1953) Production of oxygen from chloroplast preparations: photochemical oxygen production from isolated algal chloroplast fragments. Nature 172:947-948

Punnett T, Iyer RV (1964) The enhancement of photophosphorylation and the Hill reaction by carbon dioxide. J Biol Chem 239: 2335-2339

Punnett T and Kelly JH (1975). Ultrastructural transformation of chloroplasts in terrestrial plants. J Cell Biol; see Meeting Supplement abstract book; not available online, p 346a

Punnett T and Kelly JH (1976) Environmental control over C3 and photosynthesis in vascular plants. Plant Physiol (May 1976 Annual Meeting Supplement), p. 305

Punnett T, Punnett H (1963) Induction of leucocyte growth in cultures of human peripheral blood. Nature 198:1173-1175
Punnett T, Punnett HH, Kaufmann BN (1962) Preparation of a crude human leucocyte growth factor from Phaseolus vulgaris. Lancet i: $1359-1360$

Punnett T, Iyer RV, Ellinwood BW (1964) An improved method for estimation of ferrous iron and hydroquinone in the Hill reaction. Anal Biochem 7:328-334

Punnett T, Miller RL, Webb R (1980) Reanalysis of the chemical properties of two hydrozoan sperm attractants. Am Zool 20:833

Punnett T, Hilfer SR and J. Brown (1981). Chloroplast thylakoid undergo rapid rearrangements in vivo J Cell Biol; see Meeting Supplement abstract book; not available on line, p 287a

Punnett T, Miller RL, Yoo B-H (1992) Partial purification and some chemical properties of the sperm chemoattractant from the forcipulate starfish Pycnopodia helianthoides (Brandt, 1835). J Exp Zool 262:87-96

Rabinowitch E (1961) Robert Emerson (1903-1959). In: Biographical Memoirs, vol 25. National Academy of Sciences, Washington, DC, pp 112-131

Sager R, Palade G (1956) Structure and development of the chloroplast in Chlamydomonas. J Biophys Biochem Cytol 3: 463-488

Webb R, Punnett T (1989) Characterization of a Synechococcus strain PCC7002 spontaneous mutant strain defective in accumulation of Photosystem II core chlorophyll II-protein complexes. J Bacteriol 171:2262-2264 